\title{
Dissociative Excitation of Some Gaseous Organosilicon Compounds by Electron Impact
}

\author{
Hiroshi Morita, Hiroshi Sasagawa ${ }^{\ddagger}$, Hiroshi Toh ${ }^{\ddagger}$, and Kazuya Sumida \\ Graduate School of Science and Technology, Chiba University, Yayoi-cho, Inage-ku, \\ Chiba, Chiba 263, Japan \\ ${ }^{ \pm}$Department of Image Science, Faculty of Engineering, Chiba University, Yayoi-cho, \\ Inage-ku, Chiba, Chiba 263, Japan
}

\begin{abstract}
Emission spectra induced by electron impact on some gaseous organosilicon compounds were measured by a single photon counting technique. Vinyltrimethylsilane and vinyltrimethoxysilane showed emission bands assigned to decomposition products, $\mathrm{CH}, \mathrm{H}$, and $\mathrm{Si}$ atom, and trimethylsilylacetylene and Trimethyl(2-propynyloxy)silane produced $\mathrm{C}_{2}$ in addition to $\mathrm{CH}, \mathrm{H}$, and $\mathrm{Si}$ atom, indicating that $\mathrm{C}_{2}$ species was originated from $\mathrm{C}=\mathrm{C}$ moiety in the parent mlecules. From the comparison of the emission intensity of $\mathrm{Si}$ atom produced from each parent molecule, it is concluded that cleavage of $\mathrm{Si}-\mathrm{C}$ bond is easier than that of $\mathrm{Si}-\mathrm{O}$ bond. By mixing acrolein molecule into the organosilicon compounds, emission intensity of $\mathrm{Si}$ atom decreased, suggesting that acrolein molelcule interacted with the organosilicon compounds to suppress the generation of $\mathrm{Si}$ atom.
\end{abstract}

Keywords: Electron impact, Emission spectrum, Organosilicon compounds

\section{Introduction}

Chemical reactivity of organosilicon compounds have attracted much attention in developing noble processes of microfabrication [1-3] and in potential applications as thin-film photoconductors $[4,5]$ and nonlinear optical materials $[6,7]$, together with in extensive syntheses of a variety of polysilanes and polysiloxanes $[8,9]$. From some gaseous organosilicon compounds, thin films were synthesized under irradiation with UV and IR laser light using photochemical and photopolymerization reactions [10-17]. Thin films deposited from gaseous organosilicon compounds had chemical structures different from those of the parent molecules and also from those synthesized in the liquid phase. These results clearly showed that a thin-film formation from gaseous organic molecules under irradiation with laser light can afford a unique way to synthesize noble materials.

Recently, we have succeeded to produce sedimentary aerosol particles from gaseous organic molecules under irradiation with $\mathrm{N}_{2}$ laser light [18-20]. A gaseous mixture of trimethyl(2propynyloxy)silane (TMPSi) and acrolein (AC) deposited sedimentary aerosol particles which involved TMPSi in polymer matrix of polyacrolein [21]. Aerosol particles of organosilicon compounds with a size of several tens of nanometer are expected to show unique chemical behaviors and are supposed to become a constituent of microfabrication in direct patterning. To apply the method for practical use, it is necessary to understand chemical behaviors of organosilicon compounds under irradiation with electron beam and UV laser light. In the present paper, in order to investigate the dissociative excitation process by electron impact, decomposition products of some gaseous organosilicon compounds have been detected by measuring emission spectra under irradiation with electron beam, and the collisional effect of $\mathrm{AC}$ on the decomposition process has been studied.

\section{Experimental}

TMPSi was prepared by refluxing a mixture 

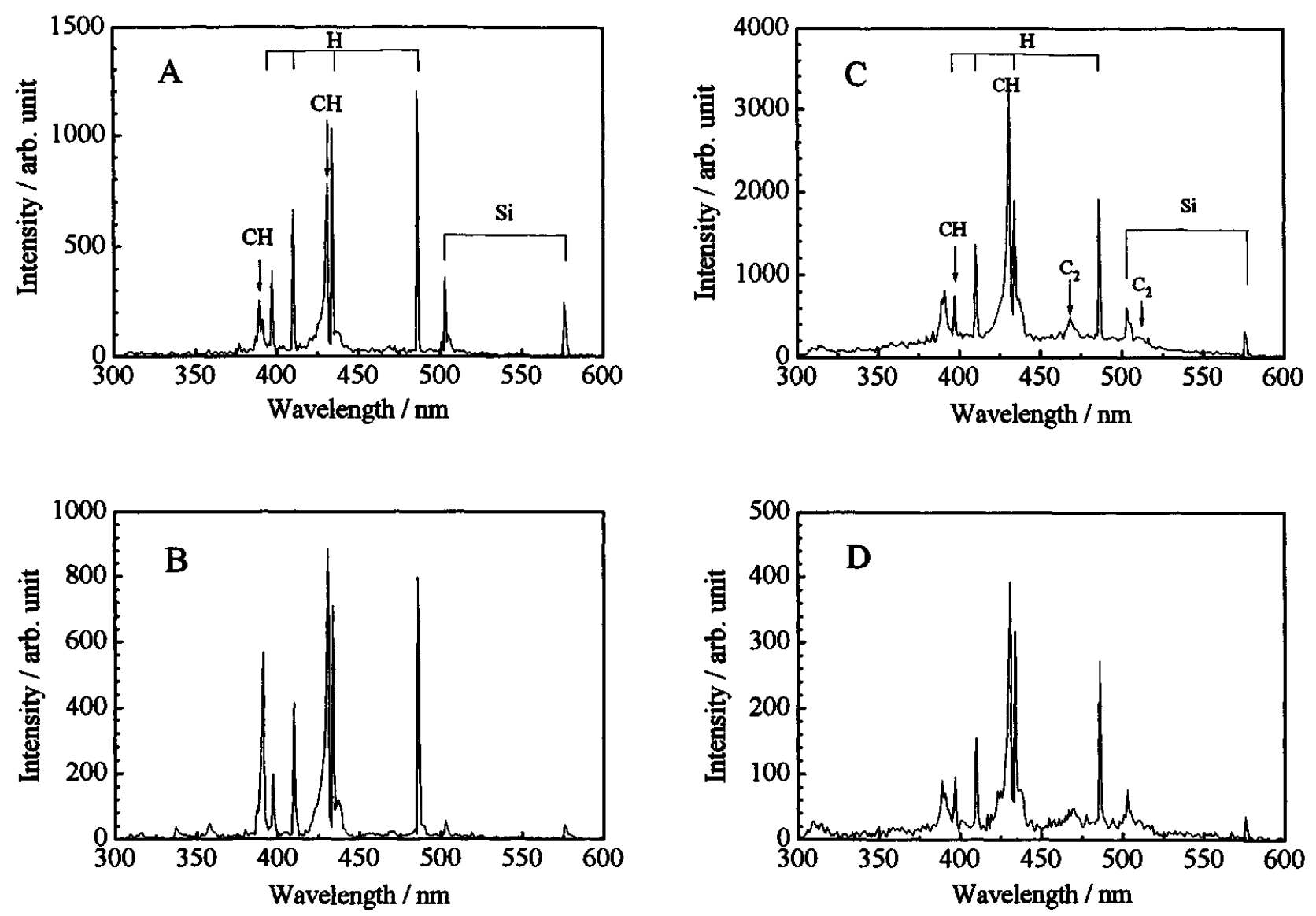

Fig. 1. Emission spectra induced by electron impact on (A) VTMeSi, (B) VTMSi, (C) TMeSiA, and (D) TMPSi at a pressure of 2 mTorr. Incident electron energy is $80 \mathrm{eV}$.

of 1,1,1,3,3,3-hexamethyldisilazane (Tokyo Kasei, GR grade, 96\%) and 2-propyn-1-ol (Wako, EP grade, $98 \%$ ) for $12 \mathrm{~h}$ under nitrogen atmosphere followed by fractional distillation [21]. Fraction at $110^{\circ} \mathrm{C}$ was used as a pure sample after checking its purity by gas chromatography. TMPSi was stored in a deaerated pyrex glass tube below $10^{\circ} \mathrm{C}$ to prevent polymerization. Vinyltrimethylsilane (VTMeSi) (Tokyo Kasei, EP grade, 98\%), vinyltrimethoxysilane (VTMSi) (Tokyo Kasei, EP grade, 99\%), trimethylsilylacetylene (TMeSiA) (Tokyo Kasei, GR grade, $98 \%$ ), and AC (Merck, $95 \%$, stabilized with $0.2 \%$ hydroquinone) were also stored in a refrigerator below $10^{\circ} \mathrm{C}$ to prevent polymerization. All the samples were degassed by freeze-pump-thaw cycles immediately before use. Each sample vapor of organosilicon compound was introduced into a collision chamber at a background pressure of $6 \times 10^{-7}$ Torr ( 1 Torr = 133.3 Pa), and exposed to pulsed electron beam at an incident electron energy of $50-100 \mathrm{eV}$. Acrolein vapor was mixed with an organosilicon compound just before entering the collision chamber. Sample pressure in the collision chamber was measured with a capacitance manometer (MKS Baratron 227A). Pulse width $(50 \mu \mathrm{s})$ of electron beam and timing for triggering a data aquisition system were controlled by a microcomputer. Photons emitted from gaseous decomposition products were detected through a monochromator (Ritsu MC-30N) and the number of photons were counted using a single photon counting technique [22] under irradiation of 3600 shots of electron beam at each wavelength.

\section{Results and Discussion}

Emission spectra induced by electron impact on gaseous VTMeSi, VTMSi, TMeSiA, and TMPSi at a pressure of $2 \mathrm{mTorr}$ are shown in Fig. 1. At an incident electron energy of $80 \mathrm{eV}$, Balmer lines of $H$ atom $(396,410,433$, and $486 \mathrm{~nm})$ and $3900 \AA$ and $4300 \AA$ systems of $\mathrm{CH}$ were observed with VTMeSi and VTMSi (Figs. 1A and 1B) in addition to 503 and $577 \mathrm{~nm}$ bands. The 503 and 
$577 \mathrm{~nm}$ bands disappeared when a filter (UV 35) was used to cut the light shorter than $350 \mathrm{~nm}$, revealing that the actual emitting wavelengths were 251 and $288 \mathrm{~nm}$. These bands can be assigned to the emission bands of silicon atom [23, 24].

Emission spectra of TMeSiA and TMPSi (Figs. 1C and 1D) exhibited Swan bands of $C_{2}$ in 450 480 $\mathrm{nm}$ and $500 \sim 520 \mathrm{~nm}$ regions in addition to the bands characteristic of $\mathrm{H}, \mathrm{CH}$, and $\mathrm{Si}$ atom. This result indicated that $\mathrm{C}_{2}$ radical was produced from acetylenic moiety of the molecules, but not from ethylenic moiety. $\mathrm{C}=\mathrm{C}$ double bond adjacent to $\mathrm{Si}$ atom was broken by electron impact.

As is shown in Fig. 1, emission intensity of $\mathrm{Si}$ atom depended on molecular structure of the parent molecules. At a sample pressure of $2 \mathrm{mTorr}$, emission intensity of the $251 \mathrm{~nm}$ and $288 \mathrm{~nm}$ bands normalized to the emission intensity of $\mathbf{4 3 1}$ $\mathrm{nm}$ band of $\mathrm{CH}$ were 0.46 and 0.32 for VTMeSi, 0.12 and 0.10 for TMeSiA, and 0.06 and 0.05 for VTMSi at an electron energy of $80 \mathrm{eV}$. At a sample pressure of $1.5 \mathrm{mTorr}$, the normalized emission intensity of $288 \mathrm{~nm}$ band of $\mathrm{Si}$ atom was 0.07 for TMPSi and 0.06 for VTMSi at an electron energy of $80 \mathrm{eV}$. Emission intensity of $\mathrm{Si}$ atom decreased in the order of VTMeSi>TMeSiA> TMPSi>VTMSi. The emission intensity of Si atom normalized to the $\mathrm{CH}$ band intensity was not sensitive to the incident electron energy between 70 100 eV. In VTMSi, Si band was not observed at an electron energy of $60 \mathrm{eV}$, but in TMPSi, $\mathrm{Si}$ band was detected at an electron energy of $60 \mathrm{eV}$, but not at $50 \mathrm{eV}$. From these results, it is concluded that cleavage of $\mathrm{Si}-\mathrm{C}$ bond is easier than that of $\mathrm{Si}-\mathrm{O}$ bond being consistent with the value of bond energy, and from the comparison between VTMeSi and TMeSiA, cleavage of Si-C bond adjacent to $\mathrm{C}=\mathrm{C}$ bond is easier than that of $\mathrm{Si}-\mathrm{C}$ bond adjacent to $\mathrm{C}=\mathrm{C}$ bond.

To investigate the interaction between the organosilicon compounds and acrolein, emission spectra induced by electron impact on gaseous mixtures of organosilicon compounds and $\mathrm{AC}$ were measured at an electron energy of $80 \mathrm{eV}$. The result on a gaseous mixture of VTMeSi ( $2 \mathrm{mTorr}$ ) and AC (1 mTorr) is shown in Fig. 2. In a preliminary experiment, emission spectrum induced by electron impact on pure $\mathrm{AC}$ was measured; $\mathrm{AC}$ produced $\mathrm{H}, \mathrm{CH}$, and $\mathrm{C}_{2}$ species at electron energies of $50-100 \mathrm{eV}$. The spectrum in Fig. 2 showed the bands characteristic of the emitting species produced from both VTMeSi and AC, except that the emission intensity of $\mathrm{Si}$ atom and Balmer lines

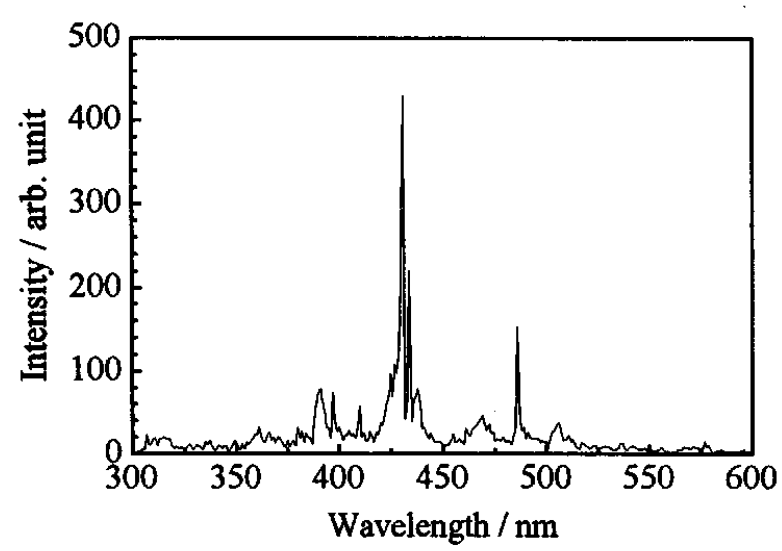

Fig. 2. Emission spectrum induced by electron impact on a gaseous mixture of VTMeSi ( 2 mTorr) and AC (1 mTorr). Incident electron energy is $80 \mathrm{eV}$.

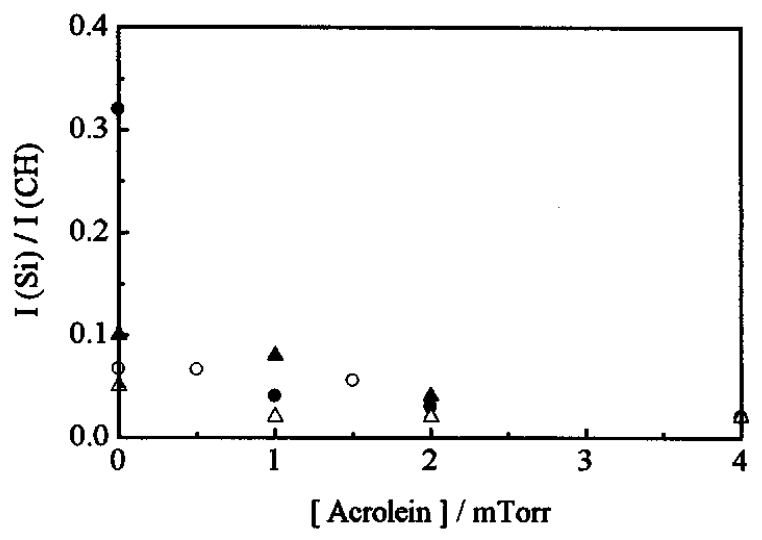

Fig. 3. Dependence of emission intensity of $288 \mathrm{~nm}$ band of Si atom induced by electron impact on gaseous mixtures of VTMeSi/AC (O), VTMSi/AC $(\triangle)$, TMeSiA/AC (A), and TMPSi/AC (O) against partial pressure of $\mathrm{AC}$. The $288 \mathrm{~nm}$ band intensity was normalized to the intensity of $431 \mathrm{~nm}$ band of $\mathrm{CH}$. Sample pressure is 2 mTorr for VTMeSi, VTMSi, and TMeSiA, and $1.5 \mathrm{mTorr}$ for TMPSi .

of $\mathrm{H}$ atom became weaker. The same spectral behaviors were observed with the gaseous mixtures of the other three organosilicon compounds and AC. The change of the emission intensity of $\mathrm{Si}$ atom was measured by varing the partial pressure of AC. As is shown in Fig. 3, AC molecules quenched the emission of $\mathrm{Si}$ atom, indicating that $\mathrm{AC}$ molecules interacted efficiently with $\mathrm{Si}$ atom, and/or Si atom formation process was suppressed by the collisional interaction between the organosilicon compounds and AC. Among the four organosilicon compounds studied in the present paper, VTMeSi was most efficiently quenched by 
AC, and TMPSi was quenched least.

In sedimentary aerosol particles deposited from a gaseous mixture of TMPSi and AC under irradiation with $\mathrm{N}_{2}$ laser light, a considerable amount of elemental silicon was detected together with silicon bonded in an organosilicon polymer [21]. In the case of a gaseous mixture of VTMSi and $A C$, elemental silicon was detected only little in the aerosol particles [25]. In the aerosol particle formation, organosilicon compound was incorporated into the aerosol particles as polymerized species, and then laser light induced the cleavage of some chemical bonds of polymerized organosilicon compound. More abundance of elemental silicon in TMPSi/AC than in VTMSi/AC under irradiation with $\mathrm{N}_{2}$ laser light can be explained by the fact that cleavage of $\mathrm{Si}-\mathrm{C}$ bond is easier than that of $\mathrm{Si}-\mathrm{O}$ bond, and formation process of elemental silicon in TMPSi/AC is not suppressed effectively by the interaction with AC molecules. These conclusions are consistent with the results observed in the present study under irradiation with electron beam, suggesting that the chemical reactivity of some organosilicon compounds against electron beam is well correlated with the reactivity against $\mathrm{UV}$ laser light.

\section{References}

1. R. D. Miller, D. Hofer, D. R. McKean, C. G. Willson, R. West, and P. Trefonas, Materials for Microlithography, L. Thompson, C. G. Willson and J. M. J. Frechet, Ed., ACS Symposium Series 266, American Chemical Soc., Washington, D. C. (1984) p 293.

2. J. M. Ziegler, L. A. Harrah, and A. W. Johnson, SPIE Adv. Resist Technol. Proc. II, 539 (1985) 166.

3. G. N. Taylor, J. M. Ziegler, M. Y. Hellman, and T. M. Wolf, Proc. SPIE, 920 (1988) 274.

4. K. Kajzar, J. Messier, and C. J. Rosilio, J. Appl. Phys., 60 (1986) 3040.

5. M. Abkowitz, F. E. Knier, H.-J. Yuh, R. J. Weagley, and M. Stolka, Solid State Commun. 62 (1987) 547.

6. P. A. Bianconi and T. W. Weidman, J. Am.
Chem. Soc., 110 (1988) 2342.

7. P. A. Bianconi, F. S. Schilling, and T. W.

Weidman, Macromolecules, 22 (1989) 1697.

8. R. D. Miller and J. Michl, Chem. Rev., 89 (1989) 1359 .

9. W. L. Wilson and T. W. Weidman, J. Phys. Chem., 95 (1991) 4568.

10. W. F. Manders and J. M. Bellama, J. Polym. Sci., Polym. Chem. Ed., 23 (1985) 351.

11. R. Alexandrescu, J. Morjan, C. Grigoriu, I. N. Michailescu, Z. Bastl, J. Tlaskal, R. Mayer, and J. Pola, Appl. Phys. A, 46 (1988) 768.

12. Z. Papouskova, J. Pola, Z. Bastl, and J.

Tlaskal, J. Macromol. Sci.-Chem. A, 27 (1990) 1015.

13. J. Pola, R. Alexandrescu, J. Morjan, and D.

Sorescu, J. Anal. Appl. Pyrol., 18 (1990) 71.

14. M. Urbanova and J. Pola, J. Anal. Appl.

Pyrol., 24 (1993) 325.

15. J. Pola, D. Pokorna, Z. Bastl, and J. Subrt, J. Anal. Appl. Pyrol., 38 (1996) 153.

16. J. Pola and H. Morita, TetrahedronLett., 38 (1997) 7809.

17. M. Urbanova, H. Morita, V. Drinek, Z. Bastl, J. Subrt, and J. Pola, J. Anal. Appl. Pyrol., in press.

18. H. Morita and M. Shimizu, J. Phys. Chem., 99 (1995) 7621.

19. H. Morita, Y. Kimura, M. Kuwamura, and T. Watanabe, J. Photochem. Photobiol., A: Chem., 103 (1997) 27.

20. H. Morita and K. Kanazawa, J. Photochem. Photobiol., A: Chem., 112 (1998) 81.

21. H. Morita, K. Semba, Z. Bastl, and J. Pola, J. Photochem. Photobiol., A: Chem., (1998) in press.

22. H. Morita, T. Sawada, and A. Inoue, $J$. Photopolym. Sci. Technol., 6 (1993) 87.

23. D. Husain and P. E. Norris, J. Chem. Soc.

Faraday Trans. II, 74 (1978) 93.

24. N. Washida, Y. Matsumi, T. Hayashi, T. Ibuki, A. Hiraya, and K. Shobatake, J. Chem. Phys., 83 (1985) 2769.

25. H. Morita, K. Semba, T. Umezawa, and M. Kuwamura, Colloid and Surfaces, $A,(1998)$ in press. 